\title{
Percutaneous retrieval of umbilical vein catheter fragment in an infant two months after embolization
}

\author{
Alper Akın¹, Meki Bilici ${ }^{1}$, Fikri Demir ${ }^{1}$, Murat Muhtar Yılmazer ${ }^{1}$, Mehmet Şah İpek ${ }^{2}$, \\ Hülya Kara ${ }^{1}$ \\ ${ }^{1}$ Division of Pediatric Cardiology, Departmant of Pediatrics, Dicle University Faculty of Medicine, Diyarbakır, ${ }^{2}$ Division \\ of Neonatalogy, Diyarbakır Memorial Hospital, Diyarbakır, Turkey. E-mail: alperakin1@hotmail.com \\ Received: 7th March 2016, Revised: 20th November 2017, Accepted: 5th April 2018
}

\begin{abstract}
SUMMARY: Akın A, Bilici M, Demir F, Yılmazer MM, İpek MŞ, Kara H. Percutaneous retrieval of umbilical vein catheter fragment in an infant two months after embolization. Turk J Pediatr 2018; 60: 191-193.

Umbilical vein catheterization is frequently preferred and a safe route of venous access especially in newborns. However, some cases with breaking and embolization of those catheters have been rarely reported. Herein we present a two-and-a-half-month-old infant being catheterized within first postnatal week and diagnosed to have embolization of the catheter fragment to conjunction of hepatic vein and right atrium. Percutaneous withdrawal of broken catheter was achieved despite several months after the embolization took place. We suggest that transcatheter removal of catheter fragment embolizations may be safe even in late diagnosis cases.
\end{abstract}

Key words: umbilical vein catheter, breaking of catheter, percutaneous retrieval.

Umbilical vein catheterization is frequently performed in the newborn period in order to provide a route for fluid/electrolyte therapy and parenteral medications. Although it is usually a safe procedure, in some instances, the umbilical vein catheter (UVC) may break and broken fragments may embolize to intravascular or cardiac structures. These fragments can safely be retrieved by transcatheter interventions. ${ }^{1,2}$ The broken catheters have been withdrawn shortly after breaking in all previous cases. Herein, we present a unique case with successful percutaneous retrieval of the catheter fragment several months following embolization.

\section{Case Report}

Two-and-a-half-month-old male infant had been evaluated for restlessness in a hospital and following determination of a hyperechogenic foreign body in his right upper abdominal quadrant on abdominal roentgenogram, he had been referred to our clinic. It was learned that he had been hospitalized for respiratory distress immediately after birth and had an umbilical vein catheterization (EPSA ${ }^{\circledR}$, Polyurethane Umbilical Catheter, 5 Fr, $20 \mathrm{~cm}$ ). Following improvement of respiratory distress, the catheter had been withdrawn and the patient had been discharged from the hospital on the seventh day. At his current evaluation heart rate was 114 beats per minute, respiratory rate was 34 breaths per minute, blood pressure was 90/65 $\mathrm{mmHg}$, and body weight was $4600 \mathrm{~g}$. Physical examination was normal. As to laboratory findings, his leukocyte, hemoglobin, and thrombocyte counts were $10.3 \mathrm{Ku} / \mathrm{L}, 11.4 \mathrm{~g} / \mathrm{dl}$, and $502 \mathrm{Ku} / \mathrm{L}$, respectively. Liver function tests were also normal (aspartate aminotransferase: $27 \mathrm{U} / \mathrm{L}$ and alanine aminotransferase: $17 \mathrm{U} / \mathrm{L}$ ). Direct roentgenogram showed a hyperechogenic stick-like appearance with a length of $11 \mathrm{~cm}$ in right upper abdominal quadrant which was thought to be a fragment of broken catheter (Fig. 1). No findings of arrhythmia or ischemia were observed on electrocardiogram. Two-dimensional echocardiography revealed that proximal end of the catheter was in hepatic vein and the distal end was extending into right atrium. We did not observe any thrombi neither around the catheter nor in intracardiac structures. Based on these findings, transcatheter retrieval of the broken 
fragment was planned and he underwent cardiac catheterization. An informed written consent was obtained from the patient's parents for the procedure. Following percutaneous insertion of a 5 French $(F)$ sheath into right femoral vein, a $5 \mathrm{~F}$ Judkins right catheter with a 0.035 -inch guidewire was introduced into the femoral vein and advanced to the inferior caval vein and right atrium. The broken fragment was caught in the right atrium with a 5F Amplatz Goose-neck ${ }^{\circledR}$ Snare (Microvena Corp., White Bear Lake, Minnesota, USA) introduced into $5 \mathrm{~F}$ Judkins right catheter and retrieved without any complication (Fig. 2). It was confirmed that the foreign body was a fragment of broken catheter. Repeat echocardiogram was completely normal. The patient was discharged from the hospital the day after intervention without any problems.

\section{Discussion}

Umbilical vein catheterization is a frequently preferred procedure in newborns, especially in low birth-weight prematures to provide a route for parenteral nutrition, intravenous medication, and blood sampling. ${ }^{1}$ It is a simple and safe intevention in experienced hands. However, a broken fragment of UVC may seldomly embolize to intravascular or cardiac structures and some newborn cases undergoing transcatheter retrieval of embolized fragments have been reported in the literature. ${ }^{1-6}$

Broken fragments in previous cases had

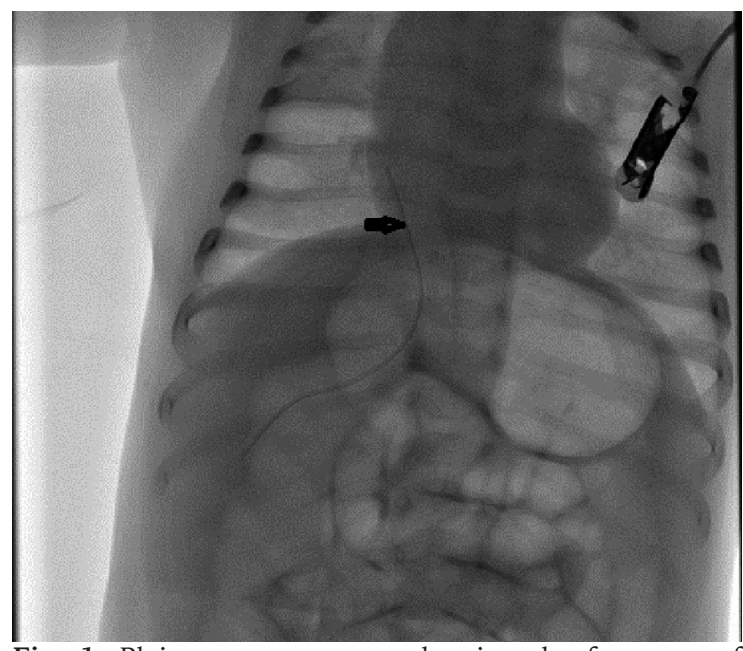

Fig. 1. Plain roentgenogram showing the fragment of umbilical vein catheter extending from hepatic structures to right atrium embolized to pulmonary artery, left atrium, and pulmonary vein. ${ }^{1-3,6}$ As to our patient, the proximal end of the catheter was in hepatic vein and the distal end was extending into right atrium. The placement of the proximal part of the broken fragment in pulmonary vein and being relatively long might have prevented embolization to distal chambers such as right ventricle and pulmonary artery.

Because of the paucity of the cases with UVC fragment embolization and retrieval of them short after displacement, serious complications have not been reported so far. However, it is theoretically possible that the clinical findings varying from arrhythmia to sudden death being observed in patients with embolized fragments of catheters used in other parts of the body may also occur in cases with broken UVC embolization. ${ }^{7,8}$ The presence of foreign bodies in systemic circulation causes a predisposition to intravascular thrombus formation. In these conditions, instead of initiation of anticoagulant therapy, immediate retrieval of the fragments are recommended. ${ }^{3}$ Interestingly, despite a twomonth delay in the diagnosis of the embolized fragment, the patient was asymptomatic and did not have catheter-related thrombus or infection.

Percutaneous retrieval of broken fragments is recommended as much as possible. Surgical removal is an alternative option. Despite it may vary according to the site of embolization, femoral vein and umbilical vein were generally preferred routes of access for transcatheter

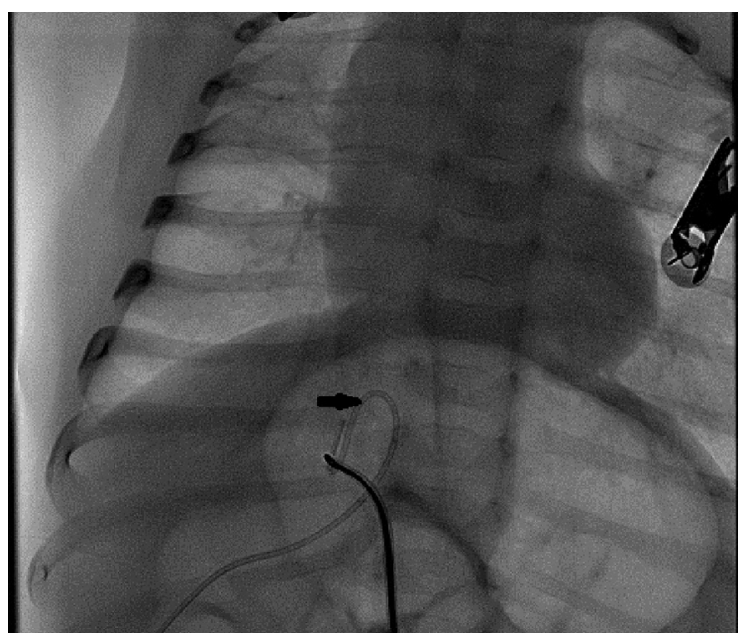

Fig. 2. Image showing distal end of catheter fragment being caught by goose-neck snare just before withdrawal 
removal.1,3,4 Amplatz goose-neck snare, loop snare, and helical basket catheter were the most frequently used devices in this manner. ${ }^{1,3,6}$ The probability of retrieval success is expected to decrease with increasing duration of catheter embolization owing to increased risk of thrombi. To our knowledge, the current case is the first in whom percutaneous withdrawal of broken catheter was achieved despite several months after the embolization took place. We suggest that transcatheter removal of catheter fragment embolizations may be performed safely even in late diagnosis cases.

In conclusion, although umbilical vein catheterization seems a safe procedure, breaking and embolization of these catheters into cardiac structures may seldomly occur. Potential serious complications necessitate immediate retrieval of the broken catheters. Percutaneous withdrawal of embolized catheters is safe and successful in the cases with several-month delay in diagnosis, as in our patient. Therefore, it should be tried even in delayed cases before referring for more invasive surgical removal.

\section{REFERENCES}

1. Nigam A, Trehan V, and Metha V. Umbilical venous catheter retieval in a $970 \mathrm{gm}$ neonate by a novel technique. Ann Pediatr Cardiol 2014; 7: 52-54.

2. Ruiz CE, Nystrom GA, Butt AI, Zhang HP. Percutaneous retrieval of a broken umbilical catheter from left atrium in a premature newborn. Cathet Cardiovasc Diagn 1995; 36: 265-268.

3. Gasparis AP, Santana D, Blewett C, Bohannon WT, Silva MB. Endoluminal Retrieval of a Dislodged Umbilical Vein Catheter A Case Report. Vasc Endovascular Surg 2004; 38: 583-586.

4. Gross DM, Cox MA, Denson SB, Ferguson L. Unique use of a tip-deflecting guide wire in removing a catheter embolus from an infant. Pediatr Cardiol 1987; 8: 117119.

5. Simon-Fayard EE, Kroncke RS, Solarte D, Peverini R. Nonsurgical retrieval of embolized umbilical catheters in premature infants. J Perinatol 1997; 17: 143-147.

6. Massin M, Lombet J, Rigo J. Percutaneous retrieval of broken silastic catheter from the left atrium in a critically ill premature infant. Cathet Cardiovasc Diagn 1997; 42: 409-411.

7. Denny MA, Frank LR. Ventricular tachycardia secondary to Port-A-Cath fracture and embolization. J Emerg Med 2003; 24: 29-34.

8. Surov A, Buerke M, John E, Kösling S, Spielmann RP, Behrmann C. Intravenous Port Catheter Embolization: Mechanisms, Clinical Features, and Management. Angiology 2008; 59: 90-97. 